\title{
FAMILIAL METAPHYSIAL DYSPLASIA
}

\author{
J. E. A. David and P. E. S. Palmer, Bulawayo, Southern Rhodesia
}

From the Bulawayo General Hospital

Familial metaphysial dysplasia is a rare disease. We have traced only eleven recorded cases and a description of a museum specimen: there is also the appearance of a femur in a Nubian grave of the Archaic period-but, from the available information, we are not convinced that this should be included.

We record here full details of another case, with unusual features, and details of the patient's relatives, two of whom are affected. A further family with less marked changes is also reported.

The disease was first described briefly by Pyle in 1931. The same case and that of the patient's sister were later reported in detail by Bakwin and Krida in 1937. The next report was that of Hermel, Gershon-Cohen and Jones (1953). Recently two cases were described by Komins (1954), three cases by Jackson, Albright, Drewry, Hanelin and Rubin (1954), and two cases by Feld, Switzer, Dexter and Langer (1955).

The diagnosis is made radiologically, and the disease appears to have little effect on the general health of the patient. It is not progressive. It is undoubtedly familial: the findings in our case suggest that it is transmitted through the male, but Jackson et al. recorded a case transmitted through the mother.

The most striking change is the extreme widening of the metaphysial ends of the long bones, with marked thinning of the cortex in the widened areas: the mid-diaphysial areas of the long bones are usually within normal limits. All the long bones and the skull may be affected.

In some of the previous cases there has been osteomalacia and a tendency towards abnormal fragility, but in our cases there was no evidence of this. The histological findings were described by Ingalls (1933), who examined a museum specimen from a man of thirty-three years who died of tuberculosis. (This same case was briefly noted by Hamann in 1910.)

\section{CASE REPORTS}

Case 1 (Family 1) - A European girl (Ann) aged eight years was admitted with acute ulcerative stomatitis. The confinement was said to have been difficult, but the child was well at birth and thrived until the age of six months, when she had an attack of what was thought to be malaria. After this it was noticed that the child had developed a squint. Apart from this she had been fairly well except for dental troubles. According to the father, her " milestones" were normal, except for walking, which was delayed.

Family history-The family relationships are complicated. Both the mother and the father had been married before and there are three children of the father by a previous marriage, all boys. The mother had a previous child, also a boy. Together they had a further three children, of whom the patient was the first, and the mother has a further child by a subsequent marriage. The father is the "common denominator" in the abnormal series, the changes occurring only in his children, one by a previous marriage. All the children's available parents are healthy. Unfortunately the family history differs if obtained from the mother or the father, and since they are no longer on speaking terms it must be regarded as unreliable. One brother and one sister have similar bone changes which will be described later, and the father states that one relative on the mother's side has webbing of the toes. 
Physical examination--The child was thin, and fifty-three inches tall. Her mentality was obviously retarded and her intelligence quotient was assessed at 46 by the educational psychologist. The face was small and narrow, with a rather beaked nose and enophthalmos giving a rather parrot-like appearance (Fig. 1). There was webbing of both hands and feet. The orbits were shrunken: the action of the left superior rectus was reduced-possibly a mechanical defect rather than neurological. There was an apparent internal strabismus. simulated because of the rather broad nose: there was bilateral microcornea with small anterior chamber, and both eyes had persistent pupillary membrane with some opacity of the posterior lens capsule on both sides. We give these eye changes in detail because they

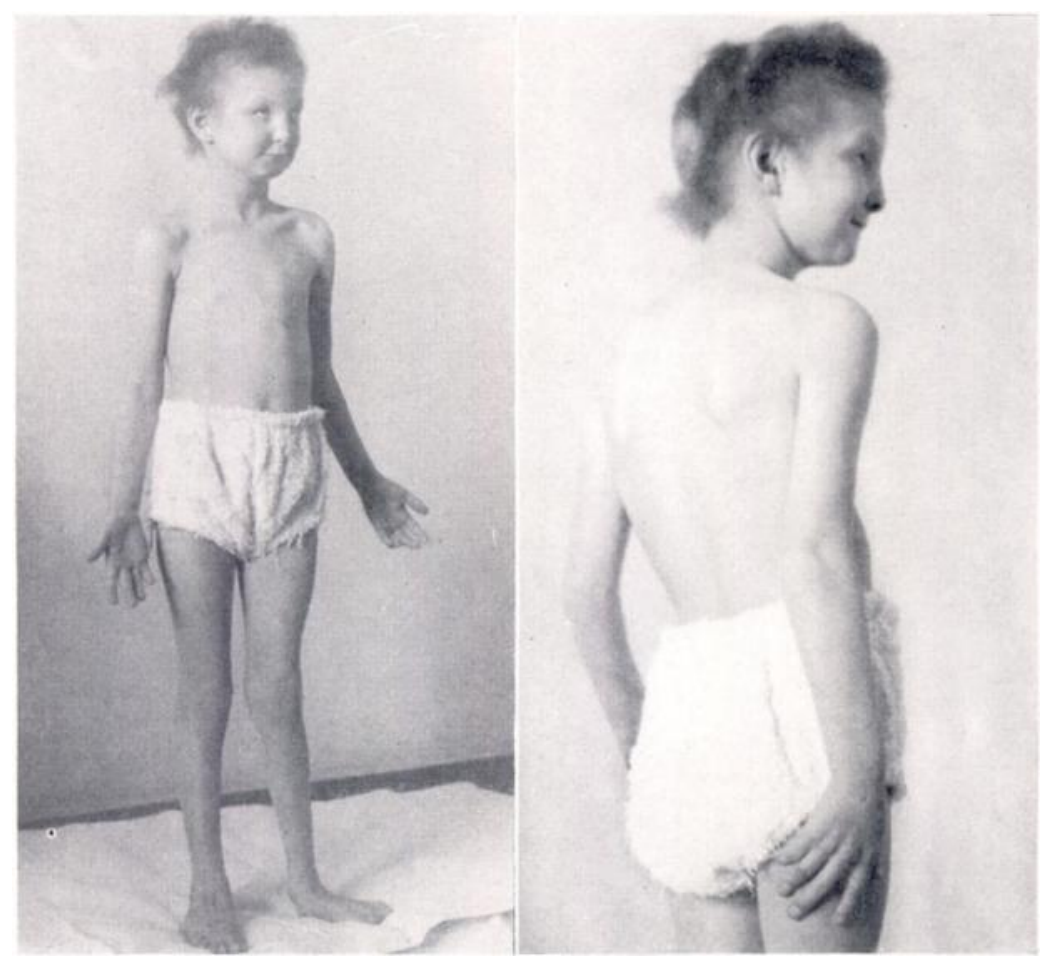

Fig. 1

Case 1-Photographs of patient.

are suggestive of arrested development at the sixth intra-uterine month, except for the posterior lens opacities which are likely to be post-natal; since there is binocular fixation these probably developed after three years. Apart from the above nothing abnormal was found on physical examination.

The following investigations were normal: blood counts, erythrocyte sedimentation rate, Wassermann reaction, blood calcium, blood sugar and serum alkaline phosphatase.

Radiographic examination-The child was originally referred for a chest radiograph and the abnormal ribs and clavicles were noted: the whole skeleton was then radiographed with the following findings. Skull-The shape was normal (Fig. 2). The vault appeared normal, but the base was greatly increased in thickness though not in density. The orbits were small, but normal otherwise. The mandible showed striking changes, giving the appearance of gross ballooning: most of the teeth, both temporary and permanent, were missing and the sockets could be seen in either jaw. The mastoids and sinuses were small; the antra were normal. The spine was normal in every respect. The pelvis and scapulae were normal. The clavicles showed marked ballooning at the inner ends (Fig. 3); they were symmetrical and 
even, but the cortex was thinned. The general appearance suggested loss of normal density. The ribs were like the clavicles: they showed ballooning, especially at the sternal ends.

Long bones-The long bones were not typical of this disease as described originally. The

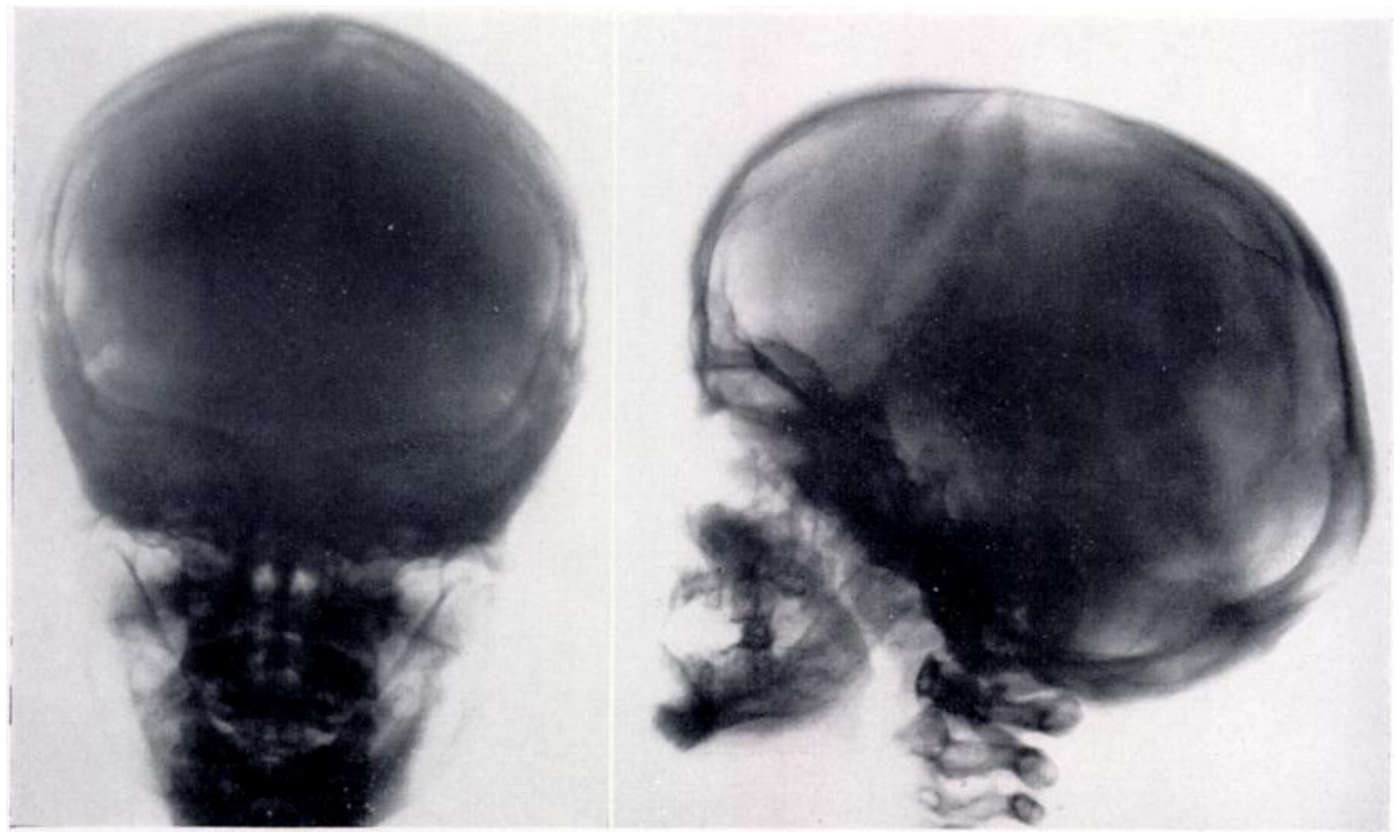

Fig. 2

Case 1-Skull.

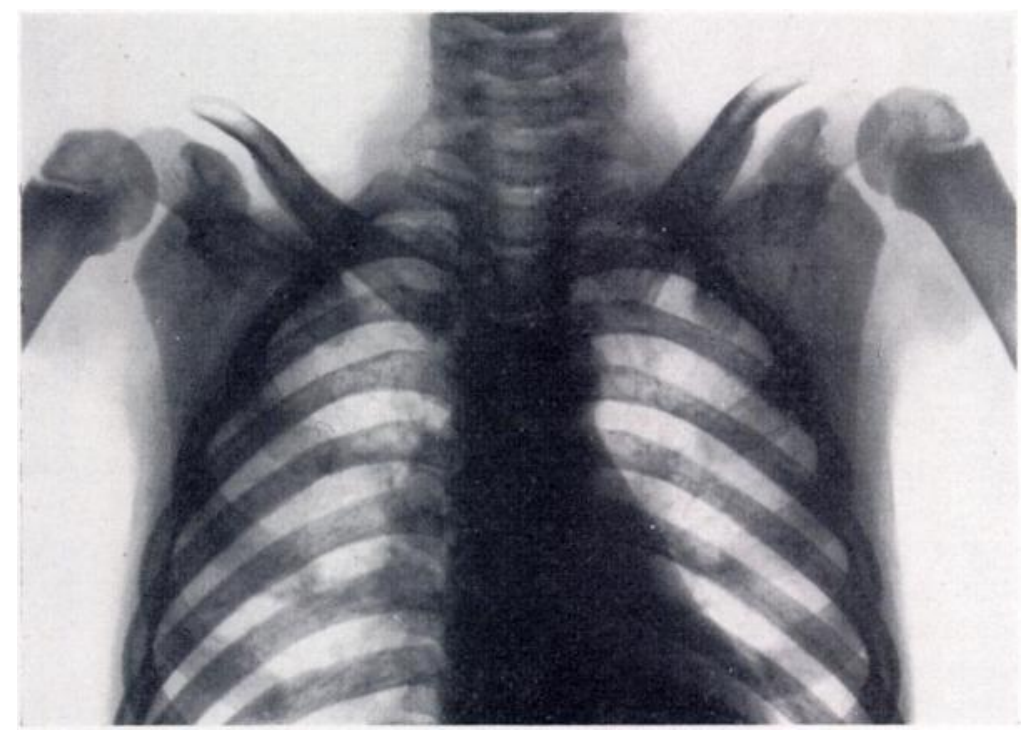

Fig. 3

Case 1-Clavicles and ribs.

mid-shafts of the radii and ulnae were widened and these bones showed generalised enlargement (Fig. 4). The shafts of the other long bones were normal (Fig. 5).

Metatarsals, metacarpals and phalanges-These showed the changes of the disease but the 


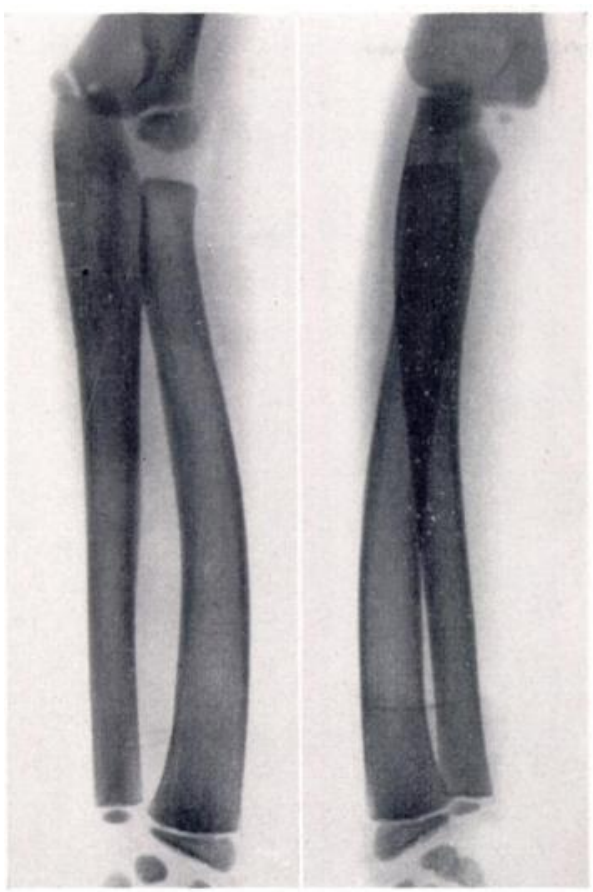

FIG. 4

Case 1-Forearm bones.

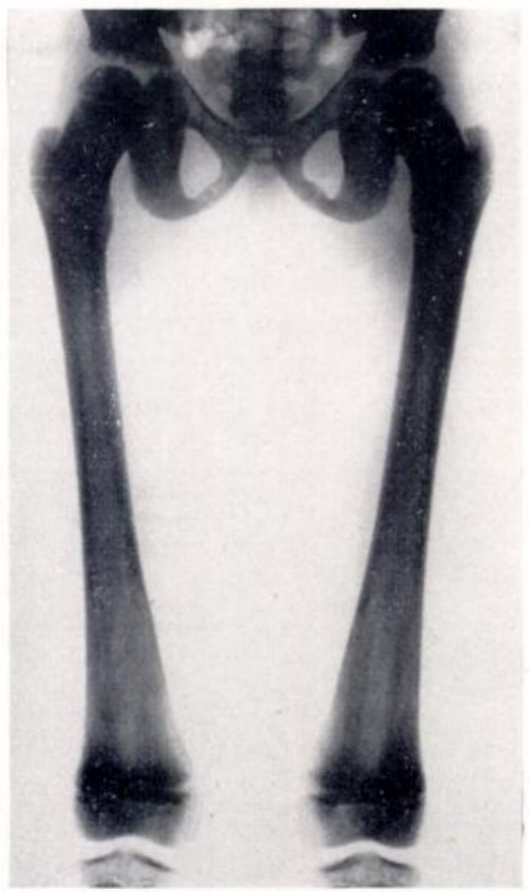

Fig. 5

Case 1-Hip joints and femora.

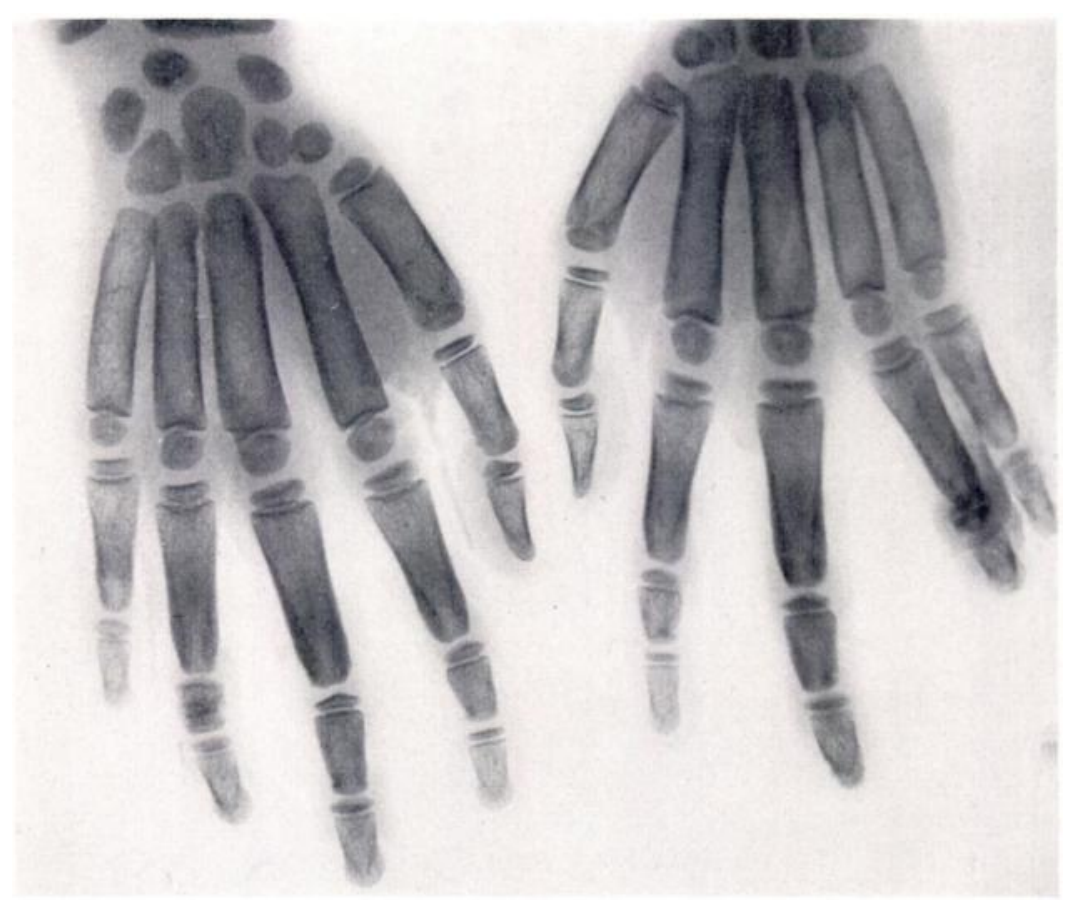

Fig. 6

Case 1-Hands.

VOL. 40 B, NO. 1, FEBRUARY 1958 
mid-shafts were also ballooned and not within normal limits (Fig. 6). There was syndactyly between the middle and ring fingers, and between the ring and little fingers, and the middle phalanx of both fifth fingers was missing; the middle phalanx of the ring finger of each hand was small and distorted.

The rate of growth and development appeared to be normal and there was no evidence of previous fractures or abnormal growth lines.

Cases 2 and 3 (Family 1)-One sister aged six years, born to the same parents, had slight changes in the forearms and legs but the skull and other bones were normal.

One half-brother aged fourteen, with the same father, had slight broadening of the lower ends of each radius and ulna, but the outline was less tubular than in the first case.

All other children in these families were normal.

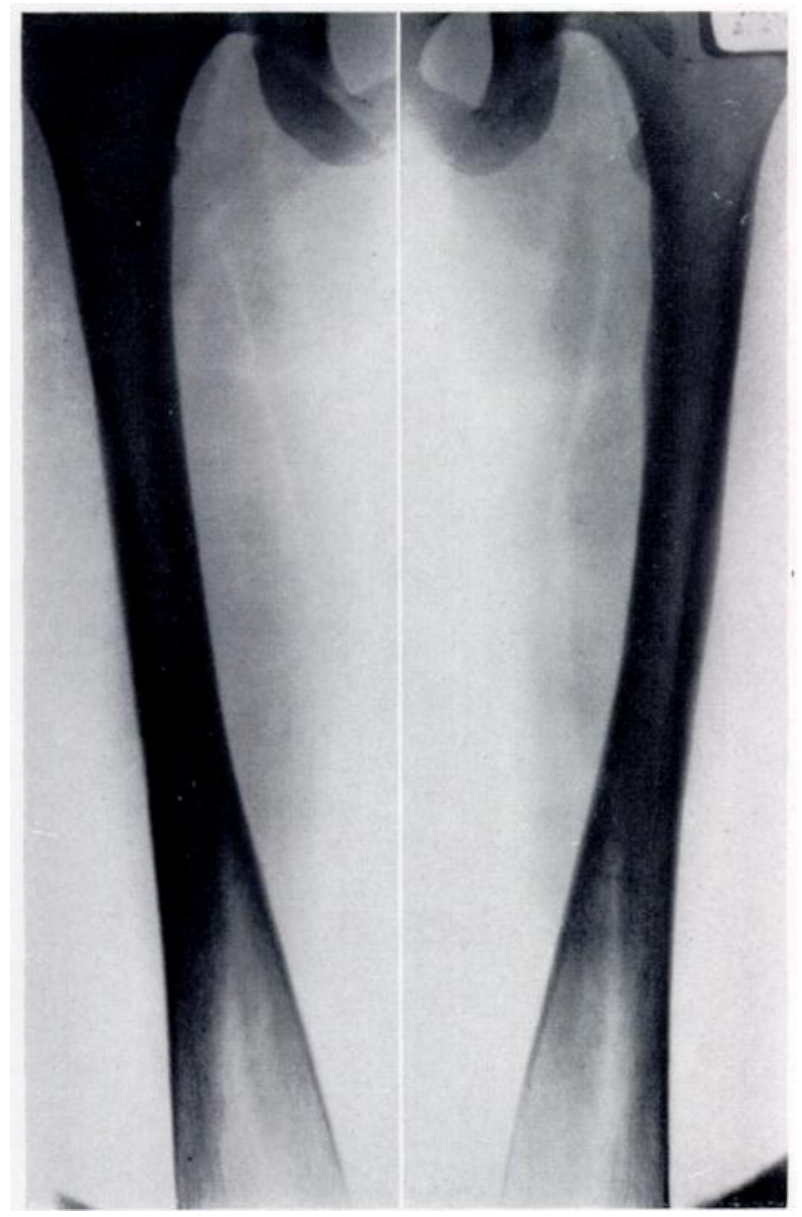

Fig. 7

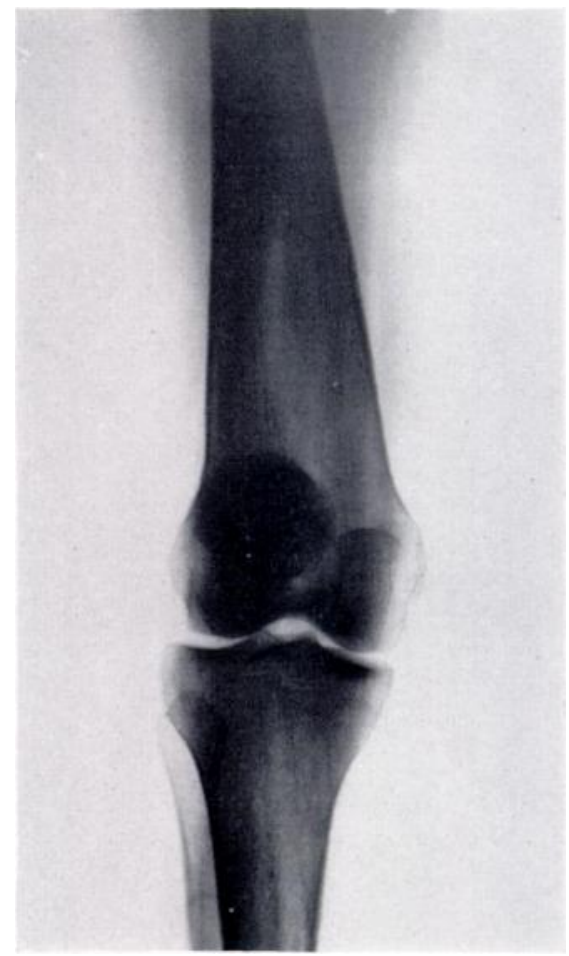

FIG. 8

Fig. 7

Case 4-Femoral shafts.

FIG. 8

Case 4-Right knee region.

Case 4 (Family 2)-A healthy European girl (Judy) aged sixteen was referred for radiography of her knees because of a rather vague history of " aching." The lower ends of both femora were widened and thinned (Figs. 7 and 8): they were flask-shaped as in Gaucher's disease, but the patient showed no evidence of any such illness. The clavicles were both broad and straight and the inner ends of the ribs were widened: the other bones were within normal limits.

Case 5 (Family 2)-One brother in a family of five showed similar changes: the children are all healthy, normally developed and intelligent. The parents refused radiographic examination. 


\section{DIFFERENTIAL DIAGNOSIS}

The findings are so unusual and so characteristic that there should be little possibility of error provided the whole skeleton is radiographed. We were at first puzzled by the skull changes, which were not noted in the original cases reported. Hermel et al. (loc. cit.) reported lack of pneumatisation in the temporal bones and Pyle (loc. cit.) mentioned a prominent frontal region. Holt and Hodges (1953) mentioned three patients with familial metaphysial dysplasia in which there was skull thickening, and Neuhauser (1953) reported a further case. While this paper was in preparation Komins (1954) reported examples of the disease with skull changes, but there are several noteworthy differences: Komins reported a large head. eyes far apart, increased density of the skull base, and hyperostosis and dental caries; whereas

TABLE I

Comparison Between Authors' Cases of Familial Metaphysial Dysplasia and Ellis's Cases of Osteopetrosis

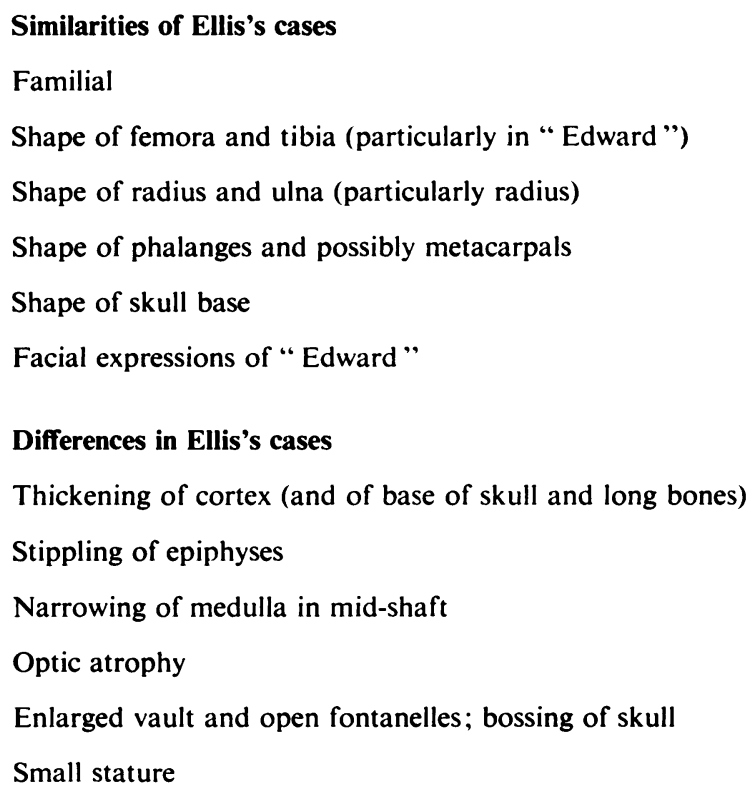

our patient had a small narrow face, enopthalmos with the eyes close together, increased thickness of the skull, but with no increase in density and no teeth. Jackson et al. (loc. cit.) recorded two examples of metaphysial dysplasia with sclerotic overgrowth of the bones of the face and base of skull resembling the changes of leontiasis ossia. He believed that the condition presented a characteristic and specific entity which he termed craniometaphysial dysplasia, and he suggested that Neuhauser's case should be placed in this group.

Similar changes and bone shapes may occur in other conditions, particularly in the femur in Gaucher's disease and in the leukaemias. In Gaucher's disease the changes are limited to the femora, and although other bones may be affected in leukaemia it is the femora that show the changes most clearly. The clubbing of the long bones may be seen in less severe types of osteogenesis imperfecta, particularly the delayed variety (Brailsford 1948), but there is a marked associated deformity and usually well developed callus remaining from previous multiple fractures; there are changes in the skull, spine and pelvis, and the mid-shafts are slender and deformed; usually the phalanges are normal. In young children, infantile 
cortical hyperostosis in its healing stage might cause confusion, but the mid-shafts are widened, and usually some callus or buttressing remains. Since no case of familial metaphysial dysplasia has been recorded at the age at which infantile cortical hyperostosis occurs, the diagnosis should not present difficulty. Hypothyroidism in young children may cause "clubbing" but the clinical appearances are different and the spine is also affected. Diaphysial aclasis can produce widening of the metaphyses, but a review of the whole skeleton will make the differential diagnosis straightforward.

There is an interesting similarity in some respects between these cases and some cases of osteopetrosis (Albers-Schönberg disease), particularly in the cases described by Ellis (1934). The similarity in shape of the bones is as striking as the difference in the density. Clearly the same growth factors are disturbed, but there is a further abnormality of calcium metabolism; a comparison of the similar and dissimilar features will demonstrate this (Table I).

Ellis himself described his two cases as being atypical in some respects, particularly in that dense bone appeared in the mid-shaft and not at the growing diaphysis. This is quite the reverse of the distribution in Albers-Schönberg disease, and it is possible that Ellis's cases were examples of familial metaphysial dysplasia, particularly as Brailsford (1948) noted that the patients were radiographed again in 1938 and that the findings were not typical of osteopetrosis. In the same paragraph he drew attention to the case described by Pyle, and did not associate Ellis's cases with this condition. Possibly Ellis's cases fall midway between the two diseases: in fact, Jackson et al. placed Ellis's cases into their group of " craniometaphysial dysplasia."

The femora in our Case 1 (Ann) are similar in shape to those illustrated by Fairbank (1951) in his description of osteopetrosis, but neither of the examples is really like those originally described by Pyle. We consider that at the present time it may be premature to subdivide metaphysial dysplasia in this way when so few cases have been described.

So far all the published cases of familial metaphysial dysplasia have factors in common, mainly those of shape; and differences, mainly those of density. The study of further cases will provide a clearer picture of the condition and its numerous variants.

\section{SUMMARY}

1. Familial metaphysial dysplasia occurring in two families is recorded.

2. One case with unusual skull changes and webbing of the digits is described in detail.

3. The similarity between the shape of the bones in familial metaphysial dysplasia and other bone disease is discussed.

We are indebted to Dr P. D. G. Quirke for the ophthalmic details, Mr J. Dowley for the intelligence tests, Dr B. Tulloch for the haematological and biochemical reports and Dr J. P. Hederman, senior radiologist in Bulawayo, for his help and advice. Sir H. A. T. Fairbank has been kind enough to read and criticise this report. One of us (P. E. S. P.) acknowledges the permission of the Secretary of Health for the Central African Federation to publish these cases.

\section{REFERENCES}

Bakwin, H., and Krida, A. (1937): Familial Metaphysial Dysplasia. American Journal of Diseases of Children, 53, 1,521.

Brailsford, J. F. (1948): The Radiology of Bones and Joints. Fourth edition, p. 560. London: J. \& A. Churchill Ltd.

Ellis, R. W. B. (1934): Osteopetrosis. Proceedings of the Royal Society of Medicine (Section for the Study of Disease in Children), 27, 1,563.

Fairbank, Sir H. A. T. (1951): Atlas of General Affections of the Skeleton, Case 24, p. 47, Fig. 71. Edinburgh and London: E. \& S. Livingstone Ltd.

Feld, H., Switzer, R. A., Dexter, M. W., and Langer, E. M. (1955): Familial Metaphyseal Dysplasia. Radiology, 65, 206. 
Hamann, C. A. (1910): An Abnormality in the Form of the Femur. Cleveland Medical Journal, 9, 710.

Hermel, M. B., Gershon-Cohen, J., and Jones, D. T. (1953): Familial Metaphyseal Dysplasia. American Journal of Roentgenology, 70, 413.

Holt, J. F., and Hodges, F. J. (1953): The Year Book of Radiology (1953-1954 Year Book Series), p. 87. Chicago: The Year Book Publishers, Inc.

Ingalls, N. W. (1933): Bone Growth and Pathology as Seen in the Femur (and Tibia). VII. Studies on the Femur. Archives of Surgery, 26, 787.

Jackson, W. P. U., Albright, F., Drewry, G., Hanelin, J., and Rubin, M. I. (1954): Metaphyseal Dysplasia, Epiphyseal Dysplasia, Diaphyseal Dysplasia, and Related Conditions. Archives of Internal Medicine, 94, 871. Komins, C. (1954): Familial Metaphyseal Dysplasia (Pyle's Disease). British Journal of Radiology, N.S. $27,670$. Neuhauser, E. B. D. (1953): Growth, Differentiation, and Disease. Caldwell Lecture, 1952. American Journal of Roentgenology, 69, 723.

Pyle, E. (1931): A Case of Unusual Bone Development. Journal of Bone and Joint Surgery, 13, 874. 